\title{
Managing Cancer And Living Meaningfully (CALM): randomised feasibility trial in patients with advanced cancer
}

\author{
Chris Lo, Sarah Hales, Aubrey Chiu, Tania Panday, Carmine \\ Malfitano, Judy Jung, Anne Rydall, Madeline Li, Rinat Nissim, \\ Camilla Zimmermann, and Gary Rodin
}

Version Post-print/accepted manuscript

Citation Lo C, Hales S, Chiu A, Panday T, Malfitano C, Jung J, Rydall A, Li M, (published version) Nissim R, Zimmermann C, Rodin G. Managing Cancer And Living Meaningfully (CALM): Randomized feasibility trial in patients with advanced cancer. BMJ Supportive \& Palliative Care. In press. doi:10.1136/bmjspcare-2015-000866

Copyright information (C) Article author(s) (or their employer(s) unless otherwise stated in the text of the article) 2017. All rights reserved. No commercial use is permitted unless otherwise expressly granted.

How to cite TSpace items

Always cite the published version, so the author(s) will receive recognition through services that track citation counts, e.g. Scopus. If you need to cite the page number of the author manuscript from TSpace because you cannot access the published version, then cite the TSpace version in addition to the published version using the permanent URI (handle) found on the record page.

This article was made openly accessible by $U$ of $T$ Faculty. Please tell us how this access benefits you. Your story matters. 


\section{Full citation and link to published version:}

Lo C, Hales S, Chiu A, Panday T, Malfitano C, Jung J, Rydall A, Li M, Nissim R, Zimmermann C, Rodin G. Managing Cancer And Living Meaningfully (CALM): Randomized feasibility trial in patients with advanced cancer. BMJ Supportive \& Palliative Care. In press.

doi: 10.1136/bmjspcare-2015-000866 [Epub 2016 Jan 19] 
Managing Cancer And Living Meaningfully (CALM): Randomized Feasibility Trial in Patients with Advanced Cancer

Chris Lo, ${ }^{1,2}$ Sarah Hales, ${ }^{1,2}$ Aubrey Chiu, ${ }^{1}$ Tania Panday, ${ }^{1}$ Carmine Malfitano, ${ }^{1}$ Judy Jung, ${ }^{1}$ Anne Rydall, ${ }^{1}$ Madeline Li, ${ }^{1}$ Rinat Nissim, ${ }^{1,2}$ Camilla Zimmermann, ${ }^{1,2,3}$ Gary Rodin ${ }^{1,2}$

${ }^{1}$ Department of Supportive Care, Princess Margaret Cancer Centre, University Health Network, Toronto, Canada;

${ }^{2}$ Department of Psychiatry, University of Toronto, Toronto, Canada;

${ }^{3}$ Department of Medicine, University of Toronto, Toronto, Canada

Correspondence to:

Gary Rodin, MD

Department of Supportive Care, 16-724

Princess Margaret Cancer Centre, University Health Network

610 University Avenue, Toronto, Canada M5G 2M9

Gary.Rodin@uhn.ca 


\section{ABSTRACT}

Background: Managing Cancer And Living Meaningfully (CALM) is a brief individual psychotherapy for patients with advanced cancer. In an intervention-only phase 2a trial, CALM showed promising results, leading to the present $2 b$ study, which introduces procedures for randomization and improved rigor in preparation for a phase 3 randomized controlled trial (RCT).

Aims: To test trial methodology and assess feasibility of a confirmatory RCT.

Design: A parallel-arm RCT (intervention vs. usual care) with 3 and 6 month follow-ups. Assessment of feasibility included rates of consent, randomization, attrition, intervention non-compliance and usual care contamination. Primary outcome: depressive symptoms (Patient Health Questionnaire-9; PHQ-9). Secondary outcomes: major depressive disorder (MDD), generalized anxiety, death anxiety, spiritual wellbeing, attachment anxiety and avoidance, self-esteem, experiential avoidance, quality of life and posttraumatic growth. Bayesian conjugate analysis was used in this low-powered setting.

Setting/participants: Sixty adult patients with advanced cancer from the Princess Margaret Cancer Centre.

Results: Rate of consent was $32 \%$, randomization $78 \%$, attrition $25 \%$, non-compliance $37 \%$ and contamination 17\%. There was support for potential treatment effects on: PHQ-9, Odds Ratio $(O R)=$ $1.48,95 \%$ Credible Interval $\left(C R I_{.95}\right)(0.65,3.38)$; $\mathrm{MDD}, \mathrm{OR}=1.56, \mathrm{CRI} .95(0.50,4.84)$; attachment anxiety, $\mathrm{OR}=1.72, \mathrm{CRI}_{.95}(0.73,4.03)$; and attachment avoidance, $\mathrm{OR}=1.58, \mathrm{CRI}_{.95}(0.67,3.71)$. There was no support for effects on the 7 remaining secondary outcomes.

Conclusions: A phase 3 CALM RCT is feasible and should aim to detect effect sizes of $d=0.40$, with greater attention to issues of compliance and contamination. Registration: ClinicalTrials.gov NCT02353546.

Keywords: affective symptoms, cancer, depression, palliative care, pilot trial, psychotherapy

Word Count: 3,349 


\section{INTRODUCTION}

Emotional disturbances are common in patients with advanced or metastatic cancer, with anxiety peaking at the time of diagnosis and again at recurrence and with depression becoming more common with disease progression and proximity to death. ${ }^{1,2}$ Depression in this context may be considered a final common pathway of distress in response to the symptom burden of disease and its interaction with protective psychosocial factors, including attachment security, self-worth and spiritual wellbeing. ${ }^{3}$ In this circumstance, the threat of mortality and the progression of disease heighten fears about dependency and suffering and call into question the values that shape meaning in life. ${ }^{4}$

Several group therapies have been developed for patients with life threatening illness, including supportive expressive, ${ }^{5-7}$ cognitive existential, ${ }^{8,9}$ and meaning-centered ${ }^{10}$ group therapies. However, the feasibility of group therapy for many patients with metastatic cancer may be limited for a number of reasons. These include problems associated with scheduling in the context of advancing illness and medical treatments, as well as the burden for patients of absorbing the emotional distress of others, when they have not yet processed their own. Also, patients may prefer private time to discuss the personal implications of recent and tragic life-altering events that can feel overwhelming. These factors, as well as disability due to the progression of disease, may contribute to the problem of attrition that has been encountered in studies of group psychotherapy with mixed samples of patients with metastatic cancer. $^{11}$

More recently, a small number of evidence-based individual psychotherapies have shown benefit with patients living with advanced disease. Dignity Therapy is based on strengthening the sense of dignity at the end of life and is primarily intended for patients near or proximate to death. ${ }^{12,13}$ Meaning-centered individual psychotherapy seeks to improve spiritual wellbeing and the sense of meaning and purpose. ${ }^{14,15}$ Its modules are delivered in a standardized format and sequence and involve a combination of didactics, experiential exercises and psychotherapeutic techniques to promote exploration of meaning and its uses in coping with advanced disease.

We have developed a brief, individual, supportive-expressive psychotherapy that focuses on both the practical and psychological problems that contribute to distress in advanced cancer. ${ }^{16}$ Managing Cancer And Living Meaningfully (CALM) shares features with the therapies described above and is characterized by: targeting of patients with an expected prognosis of 12-18 months; an individualized format; focus on four broad domains of disease experience that were empirically identified in metastatic cancer; and, attention to the process of mentalization and to attachment security. Mentalization refers to the capacity to reflect on feeling states, to distinguish them from literal facts, and to accept the possibility of multiple perspectives. ${ }^{17}$ Support for mentalization within the therapeutic context may help individuals to understand the personal meaning of disease while also facing its literal reality. ${ }^{4}$ Attachment security, which refers to internalized expectations of emotional support from significant others and the flexible capacity to make use of it, ${ }^{18}$ has been shown to be an important mediator of distress ${ }^{3}$ and spiritual wellbeing ${ }^{19}$ in patients with advanced cancer and is a potential target of psychotherapeutic interventions. $^{20}$ 
In an intervention-only phase 2 a pilot trial of 50 patients with advanced cancer, CALM was associated with reductions in depressive symptoms and death anxiety and an increase in spiritual wellbeing. ${ }^{21}$ These results were promising, leading to the present phase $2 \mathrm{~b}$ pilot trial in which we have introduced procedures for randomization and improved rigor in preparation for a phase 3 confirmatory study. The purpose of this phase was to test trial methodology and assess feasibility issues for a large scale RCT.

\section{METHODS}

\section{Trial Design}

This phase $2 \mathrm{~b}$ pilot was a parallel-arm RCT with intervention and usual care arms. Assessments were at baseline (t0), 3 months (t1) and 6 months ( $\mathrm{t} 2$ ), which was the endpoint of interest. The primary outcome was depressive symptoms assessed by the Patient Health Questionnaire-9 (PHQ-9). ${ }^{22}$ Secondary outcomes were diagnosis of major depressive disorder (MDD), generalized anxiety, death anxiety, spiritual wellbeing, attachment security, self-esteem, experiential avoidance, quality of life and posttraumatic growth. Intervention participants completed a measure assessing self-reported therapeutic benefit at $\mathrm{t} 1$ and $\mathrm{t} 2$. This study was approved by the University Health Network (UHN) Research Ethics Board and registered with ClinicalTrials.gov (NCT02353546).

\section{Participants}

Participants were outpatients with advanced or metastatic cancer attending the Princess Margaret Cancer Centre, University Health Network, in Toronto, Canada. Eligibility criteria included adult age; English fluency; and a confirmed diagnosis of Stage IIIB or IV lung cancer, Stage III or IV ovarian or fallopian tube cancer, Stage IV endocrine, breast, gastrointestinal, genitourinary or gynecologic cancer, or pancreatic cancer at any stage due to the aggressiveness of this illness (all diagnoses consistent with an expected prognosis of 12-18 months). Exclusion criteria included cognitive impairment found on the Short Orientation-Memory-Concentration Test ${ }^{23}$ administered at recruitment; and actively receiving inhospital psychiatric or psychological treatment.

\section{Procedure}

Outpatient clinic lists were screened and patients with advanced cancer were mailed introductory letters concerning the study. Patients were recruited by research staff while attending clinic appointments. The study was described to patients who upon providing written informed consent, were randomized after completing a t0 assessment. Usual care participants were offered the option of CALM at study end.

\section{Randomization}

The randomization sequence was created by Dr. Chris Lo using a table of random digits. Simple randomization was employed with 1:1 allocation between arms. Research staff were blinded to the sequence, which was written on cards and sealed in envelopes to be opened at assignment.

\section{Intervention}

CALM is a brief, manualized, individual psychotherapy consisting of 3-6 sessions delivered over 3-6 months that addresses four empirically derived domains: symptom management and communication with health care providers, changes in self and relations with close others, sense of meaning and purpose, and concerns related to the future and mortality. ${ }^{16,21,24}$ CALM is individualized in that it is 
tailored to the particular needs of the patient in content and process. Domains are explored with every patient but the sequence and attention to each is dependent on their salience to participants during each session. CALM domains are not standardized modules that are delivered in a set sequence, but are a framework by which therapists explore patient experience. Related to the importance of attachment security and the family as the unit of care, the participant's primary caregiver, most often the spouse or partner, adult son or daughter, is invited to join one or more sessions as deemed appropriate by therapist and patient. Caregivers did not complete any measures.

The number of sessions received is determined by the rate of reduction of distress and resolution of difficulties within each domain, and by such other factors as the patient's functional capacity and ability to attend sessions. CALM includes attention to practical needs, development of a therapeutic relationship, support for mentalization, interpretation and the joint creation of meaning, and renegotiation of attachment security. The 3-6 month time frame and the recommendation of 1 session per month was based on our team experience about the most feasible duration and frequency of sessions that would allow for alleviation of distress and improved adaptation to disease, taking into account interruptions in therapy due to scheduling difficulties, cancer treatment side effects and disease progression. Therapists aim to deliver a minimum of 3 sessions within 3 months and participants are deemed compliant with intervention when they receive this number. CALM was delivered by trained clinicians in the Department of Supportive Care at the Princess Margaret. Weekly group supervision of therapists was provided by Drs. Gary Rodin and Sarah Hales to discuss case formulation, treatment goals and appropriate CALM intervention, and to ensure treatment adherence and skill development.

\section{Usual Care}

Usual care included access to psychosocial services provided by social workers, psychologists and psychiatrists in the Department of Supportive Care. Referral at our centre occurs in approximately 33\% of advanced cancer patients, of whom $66 \%$ are seen by a social worker and $33 \%$ are seen by a psychiatrist or psychologist. ${ }^{25}$ Most psychosocial care is therefore provided by social workers and involves brief supportive interactions and instrumental assistance without psychotherapy. For patients referred to a psychologist or psychiatrist, care involves diagnostic consultation, treatment with pharmacotherapy if needed, and/or brief psychotherapy that is integrative in nature and may draw on cognitive behavioral, interpersonal, psychodynamic or other techniques depending on need and clinician training.

\section{Measures}

Physical symptom burden was measured using a brief version of the Memorial Symptom Assessment Scale, ${ }^{26}$ assessing the severity of 28 common physical symptoms of cancer in the past week.

The primary outcome was depressive symptoms measured by the PHQ-9. ${ }^{22}$ Major depressive disorder (MDD) diagnosis was made using the depression component of the Mood Disorders and Optional Disorders Module of the Structured Clinical Interview for DSM Disorders (SCID). ${ }^{27}$ SCID interviews were conducted by 3 consistent research staff, trained and monitored with monthly case-review by Dr. Madeline Li, a cancer psychiatrist blinded to randomization and PHQ-9 scores. Generalized anxiety was assessed with the Generalized Anxiety Disorder-7 (GAD-7). ${ }^{28}$ 
Death anxiety was measured using the 15 -item Death and Dying Distress Scale. ${ }^{29}$ Spiritual wellbeing was measured with the 12-item Functional Assessment of Chronic Illness Therapy-Spiritual Well-being Scale. ${ }^{30}$ Attachment security refers to the capacity to rely on and trust others during times of need and was assessed with the 16-item Modified Experiences in Close Relationships scale. ${ }^{18}$ The scale measures the dimensions of attachment anxiety (i.e. fear of abandonment by others) and attachment avoidance (i.e. defensive independence with minimization of distress). Self-esteem was measured using the 10item Rosenberg Self-esteem Scale. ${ }^{31}$ Experiential avoidance refers to the tendency to avoid and reject negative emotions and was measured using the 10-item Acceptance and Action Questionnaire-II. ${ }^{32}$

Quality of life was measured with the 14-item Quality of Life at the End of Life-Cancer Scale. ${ }^{33}$

Posttraumatic growth was measured by the Posttraumatic Growth Inventory, ${ }^{34}$ a 21 -item scale assessing positive psychological changes (e.g. greater appreciation of life, spiritual change and relational growth) after traumatic experiences, including cancer. Therapeutic benefit from CALM was assessed with the 13item Therapeutic Realizations Scale-Revised. ${ }^{35}$ Items are rated from 0-3, where 0 refers to "no benefit", 1 "some", 2 "quite a bit", and 3 "a great deal".

\section{Sample Size}

Based on Hertzog's guidelines for pilot work, ${ }^{36}$ a total sample size of 60 was chosen as offering an acceptable trade-off between power and the dedication of resources at this phase of study, allowing for detection of only large effects equal to eta-squared of 0.14 with $90 \%$ confidence between 0.04 to 0.31 .

\section{Statistical Analyses}

Data analysis was assisted by SAS/STAT software, Version 9.3. ${ }^{37}$ Feasibility was assessed by rates of consent; randomization; attrition; non-compliance with intervention, defined as the percentage of CALM participants who received less than 3 sessions; and contamination of usual care, defined as the percentage of usual care participants who received 2 or more sessions with a CALM-trained therapist over the study period.

Inherent in the design of this RCT are hypotheses that intervention participants will show greater improvement relative to control participants. Traditional significance testing in a low-powered setting may be problematic and therefore a Bayesian approach was taken to investigate the likelihood of treatment effects, focusing on the $t 2$ endpoint. ${ }^{38,39}$ This was a conjugate analysis using an approximate normal likelihood for the logarithm of the odds ratio (OR) as a statistical model. Study data was used to update a prior probability distribution of the log OR, yielding a posterior distribution that allows for intuitive inferences about the probability of an effect. In essence, a prior estimate of the OR is averaged with that found in the study to produce a posterior estimate for interpretation. No interim or dosage analyses were planned or conducted.

On self-reported outcomes, individuals were categorized as showing clinical improvement or not at t2 relative to baseline. Changes score thresholds indicating improvement were chosen which equated to effect sizes on the order of $d=0.40$, consistent with the magnitude of effects found in prior research. ${ }^{40}$ The exception was self-esteem for which a minimal 2 point raw score difference equated to $d=0.60$. 
OR's were calculated to compare the odds of improvement between arms. Concerning the SCID, analysis simply focused on the odds of depression diagnosis between arms. Attrition rates among MDD cases were examined to see whether a decrease in the odds of MDD in the intervention arm may be due to greater attrition of MDD cases in that arm relative to usual care.

Conjugate analyses were conducted on all outcomes. Skeptical priors were chosen centered on an OR of 1 , i.e. no effect. For improvement outcomes, the variance of the prior distribution was set to equal the variance of the observed data at $\mathrm{t} 2$, essentially weighting the prior with an equivalent sample size. ${ }^{51}$ For the SCID, the prior was modeled on the baseline distribution of MDD cases. The posterior distributions were summarized by a mean estimate and $95 \%$ credible intervals. Based on the posterior distribution, we calculated the probability of a treatment effect greater than an OR of 1.25 (i.e. a $25 \%$ increase in the odds of improvement), a reasonable criterion for a clinically meaningful difference between groups.

\section{RESULTS}

\section{Feasibility and Descriptive Statistics}

Recruitment occurred from June 2011 to February 2012; 75\% (237/316) of individuals were eligible for study, of whom, 32\% (77/237) consented to participate, and of whom, 78\% (60/77) were randomized (see Figure 1). Sample characteristics are shown in Table 1. Intervention and usual care groups were well matched, both being mostly married, female, Caucasian, and diagnosed with gastrointestinal cancer. Twenty-six percent (8/30) of intervention participants brought a primary caregiver to a session. Only 1 individual brought a caregiver twice.

Non-compliance with intervention was $37 \%(11 / 30)$ and contamination of usual care was $17 \%(5 / 30)$ (see Figure 1). The attrition rate by study end was $25 \%$ (15/60) (see Figure 1). For intervention participants, the mean $\mathrm{t} 1$ assessment occurred 3.83 months, $\mathrm{SD}=0.62$, after trial entry and the t2 assessment, 6.59 months, $\mathrm{SD}=0.61$. For usual care, the mean $\mathrm{t} 1$ assessment occurred 3.71 months, $\mathrm{SD}=$ 0.59 , after trial entry and the $\mathrm{t} 2$ assessment, 6.59 months, $\mathrm{SD}=0.57$.

The change score thresholds used to identify participants who improved on self-reported outcomes are shown in Table 2. The odds of improvement and MDD diagnosis are described in Table 3.

\section{Primary Outcome}

The PHQ-9 posterior distribution is summarized in Table 4. There was support for a potential treatment effect, with $66 \%$ probability of an OR $>1.25$. Intervention participants were estimated to have 1.48 times greater odds of improvement than usual care participants.

\section{Secondary Outcomes}

The posterior distributions offered support for potential effects on 3 of 10 secondary outcomes: MDD diagnosis, attachment anxiety and attachment avoidance (see Table 4).

On MDD, there was a $65 \%$ probability of an $\mathrm{OR}>1.25$. Usual care participants were estimated to have 1.56 times greater odds of MDD diagnosis than intervention participants. Note that attrition rates of MDD cases were comparable between arms. The 5 MDD cases in the intervention arm all presented at 
baseline with MDD and attrition was $0 \%(0 / 5)$ at 3 months and 40\% (2/5) at 6 months. In usual care, there were $8 \mathrm{MDD}$ cases over the study period. They were all assessed at baseline and attrition was $0 \%$ $(0 / 8)$ at 3 months and $38 \%(3 / 8)$ at 6 months.

On attachment anxiety, there was a $76 \%$ probability of an $\mathrm{OR}>1.25$. Intervention participants were estimated to have 1.72 times greater odds of improvement than usual care participants. On attachment avoidance, there was a $71 \%$ probability of an OR $>1.25$. Intervention participants were estimated to have 1.58 times greater odds of improvement than usual care participants.

\section{Therapeutic Benefit}

Table 5 presents descriptive statistics on self-reported therapeutic benefit. Most item means ranged from 1 to 2 indicating mild ("some") to moderate ("quite a bit") benefit. The most highly rated items were the chance to unburden and express feelings and the experience of reassurance and encouragement.

\section{DISCUSSION}

The results of this pilot study support the feasibility of conducting a phase 3 RCT of CALM in patients with advanced cancer. We found that $32 \%$ of eligible individuals from a non-referred outpatient population consented to participate over a nine month recruitment period, of whom $78 \%$ were randomized. As a result of recruitment earlier in the course of disease and of more systematic follow-up, the attrition rate of $25 \%$, was substantially less than the attrition rate of $68 \%$ observed in our previous intervention-only pilot trial. $^{21}$

Non-compliance with intervention was comparable in both pilots, with $37 \%$ of participants receiving less than 3 sessions in this trial, compared to $42 \%$ in the earlier study. ${ }^{21}$ Greater accommodation in appointment scheduling, based on patient availability and timely recruitment before progressive physical decline can facilitate compliance. However, attendance at sessions is dependent on many factors, such as functional capacity, severity of physical symptoms and conflicting medical appointments or interventions that are beyond the control of the patient or the research team. Contamination of usual care was found to be present in $17 \%$. More rigorous monitoring is needed to ensure that usual care participants referred to psychosocial services at our centre are treated by therapists who have not been exposed to CALM therapy. More detailed documentation of other psychiatric and psychosocial treatments that were received is also needed in a phase 3 trial to clarify treatment efficacy.

The most commonly reported therapeutic benefits of CALM were reassurance and the opportunity for emotional expression. These effects are consistent with the supportive-expressive foundations of CALM and its emphasis on the provision of reflective space and support within a therapeutic relationship. Most benefits were rated in the mild to moderate range. This magnitude of effect may relate to the quality of intervention, the measurement tools, and the recruitment of non-distressed individuals. Refinement of the supervision with regard to ongoing case formulation, monitoring and addressing therapeutic challenges and persistent distress, supporting mentalization, and ensuring adequate attention to all four domains may improve outcomes. The rigor of a future trial and the demonstration of benefit may also 
be improved by the use of a tailored measure to assess the benefits of the intervention in relation to CALM domains and by establishing a cut-off point on the primary outcome as an entry criterion.

This pilot study was not powered to confirm treatment efficacy and therefore caution is warranted concerning the interpretation of effects. There was support for potential treatment effects on PHQ-9, with $66 \%$ chance of an OR $>1.25$, and on MDD, with $65 \%$ chance of an OR $>1.25$. CALM participants were estimated to have 1.48 times greater odds of improvement on PHQ-9; usual care participants were estimated have 1.56 times greater odds of MDD compared to CALM participants. There was $76 \%$ chance of an OR $>1.25$ on attachment anxiety and $71 \%$ chance of an OR $>1.25$ on attachment avoidance. CALM participants were estimated to have 1.72 times greater odds of improvement on attachment anxiety and 1.58 times greater odds of improvement on attachment avoidance than usual care participants. These findings are consistent with previous research demonstrating that attachment security is responsive to psychotherapy ${ }^{20}$ and with a qualitative study indicating that CALM helped participants to resolve relational problems. ${ }^{24}$ Attachment security may be particularly amenable to therapeutic intervention because the threat posed by illness and death and the anticipation of increasing dependency needs heightens the salience of attachment security. ${ }^{3,4}$ There was no support for effects on the 7 remaining secondary outcomes, for which the probability of an OR > 1.25 was found to range from $8 \%$ to $34 \%$. Overall, a phase 3 trial should be prepared to detect effect sizes on the order of $d=0.40$.

Study limitations include the small sample size and its representativeness since a majority of participants were married, well-educated, English-speaking, Caucasian and female with advanced gastrointestinal cancer. The study was unblinded, which may also have affected study outcomes. Participants were not selected based on elevated distress scores, which may have limited the demonstration of benefit.

\section{Conclusions}

Phase 3 RCT's of CALM, which are needed to test efficacy, are feasible to conduct in patients living with advanced cancer. Treatment effects may be enhanced by improving compliance with intervention and by reducing contamination of usual care. Phase 3 trials of CALM should be powered to detect effect sizes of $d=0.40$. 


\section{What is already known on this topic}

Psychological distress is common in patients living with advanced cancer.

Individual psychotherapies, such as Dignity Therapy and Meaning-Centered Psychotherapy, have been shown to be of benefit in this population. The former is typically delivered close to the end of life and the latter with standardized sessions typically in a group format.

Managing Cancer And Living Meaningfully (CALM) is a brief, supportive-expressive psychotherapy that addresses practical and treatment-related issues and that supports reflection and mentalization across domains that are relevant to patients with advanced cancer.

CALM is tailored in its content and process and targets individuals with an expected prognosis of 12-18 months.

In an earlier non-randomized pilot trial, CALM was associated with reductions in depressive symptoms and death anxiety and with growth in spiritual wellbeing.

\section{What this study adds}

Evidence that: 1. A large-scale randomized controlled psychotherapy trial is feasible in patients living with advanced cancer;

2. The ability to determine treatment efficacy in a future trial may require measures to improve compliance with intervention and contamination of usual care; and

3. A phase 3 trial should be powered to detect effect sizes of $d=0.40$. 


\section{Contributors}

The study was conceived and designed by $C L, S H$ and $G R$, with refinements made by AC, TP, CM, JJ, AR, RN and CZ. ML supervised SCID training and administration. Data analysis was conducted by CL. All authors contributed to drafting the manuscript, the interpretation of results, and have read and approved the final version. The guarantors are $\mathrm{CL}, \mathrm{SH}$ and $\mathrm{GR}$.

\section{Funding}

This study was funded by research grants from the University Health Network Department of Psychiatry and the Canadian Institutes of Health Research (CIHR \#MOP 106473). This research was also supported by the Princess Margaret Cancer Foundation Hertz Centre and Kirchmann Funds, the Campbell Family Cancer Research Institute and the Ontario Cancer Institute at the Princess Margaret Cancer Centre, and by the Ontario Ministry of Health and Long Term Care (OMOHLTC). Dr. Rodin is also supported by the University of Toronto/University Health Network Harold and Shirley Lederman Chair in Psychosocial Oncology and Palliative Care. The funders had no role in the final design, analysis and writing of this study. The views expressed do not necessarily reflect those of the funders.

\section{License for Publication}

The Corresponding Author has the right to grant on behalf of all authors and does grant on behalf of all authors, an exclusive licence (or non exclusive for government employees) on a worldwide basis to the BMJ Publishing Group Ltd to permit this article (if accepted) to be published in BMJ Supportive and Palliative Care and any other BMJPGL products and sublicences such use and exploit all subsidiary rights, as set out in our licence (http://group.bmj.com/products/journals/instructions-for-authors/licenceforms).

Competing Interest: None declared.

Data sharing: No additional data available.

\section{Acknowledgements}

We would like to thank the participants for their time and effort to complete this study. We also thank our CALM therapists, Valerie Heller, Cheryl Kanter, Rhonda Kibrick-Lazear, Jenny Shaheed, Fiorella Lubertacci, and Judy Lin for their valuable contributions to this study. 


\section{REFERENCES}

1. Li M, Boquiren VM, Lo C, et al. Depression and anxiety in supportive oncology. In: Davis M, Feyer P, Ortner P, Zimmermann C (eds) Supportive Oncology. Philadelphia: Elsevier, 2011, pp. 528-540.

2. Lo C, Zimmermann $C$, Rydall AC, et al. Longitudinal study of depressive symptoms in patients with metastatic gastrointestinal and lung cancer. J Clin Oncol 2010; 28: 3084-3089.

3. Rodin G, Lo C, Mikulincer M, et al. Pathways to distress: the multiple determinants of depression, hopelessness, and desire for hastened death in metastatic cancer patients. Soc Sci Med 2009; 68: 562-569.

4. Rodin G. Individual psychotherapy for the patient with advanced disease. In: Chochinov H, Breitbart W (eds) Handbook of Psychiatry in Palliative Medicine. London: Oxford University, 2009, pp. 443-453.

5. Spiegel D, Bloom JR and Yalom I. Group support for patients with metastatic cancer: a randomized outcome study. Arch Gen Psychiatry 1981; 38: 527-533.

6. Classen C, Butler LD, Koopman C, et al. Supportive-expressive group therapy and distress in patients with metastatic breast cancer: a randomized clinical intervention trial. Arch Gen Psychiatry 2001; 58: 494-501.

7. Bordeleau L, Szalai JP, Ennis M, et al. Quality of life in a randomized trial of group psychosocial support in metastatic breast cancer: overall effects of the intervention and an exploration of missing data. J Clin Oncol 2003; 21: 1944-1951.

8. Kissane DW, Bloch S, Smith GC, et al. Cognitive-existential group psychotherapy for women with primary breast cancer: a randomised controlled trial. Psychooncology 2003; 12: 532-546.

9. Kissane DW, Love A, Hatton A, et al. Effect of cognitive-existential group therapy on survival in early-stage breast cancer. J Clin Oncol 2004; 22: 4255-4260.

10. Breitbart W, Gibson C, Poppito SR, et al. Psychotherapeutic interventions at the end of life: a focus on meaning and spirituality. Can J Psychiatry 2004; 49: 366-372.

11. Applebaum AJ, Lichtenthal WG, Pessin HA, et al. Factors associated with attrition from a randomized controlled trial of meaning-centered group psychotherapy for patients with advanced cancer. Psychooncology 2012; 21: 1195-1204.

12. Chochinov HM, Hack T, Hassard T, et al. Dignity Therapy: a novel psychotherapeutic intervention for patients near the end of life. J Clin Oncol 2005; 23: 5520-5525. 
13. Juliao M, Barbosa A, Oliveira F, et al. Efficacy of dignity therapy for depression and anxiety in terminally ill patients: Early results of a randomized controlled trial. Palliat Support Care 2013; 11: 481-489.

14. Breitbart W, Poppito S, Rosenfeld B, et al. Pilot randomized controlled trial of individual meaningcentered psychotherapy for patients with advanced cancer. J Clin Oncol 2012; 30: 1304-1309.

15. Thomas LP, Meier EA and Irwin SA. Meaning-Centered Psychotherapy: a form of psychotherapy for patients with cancer. Curr Psychiatry Rep 2014; 16: 488.

16. Hales S, Lo C and Rodin G. Managing Cancer And Living Meaningfully (CALM) treatment manual: an individual psychotherapy for patients with advanced cancer. (C2010, Princess Margaret Hospital, University Health Network, Toronto, Canada.

17. Fonagy P, Gergely G, Jurist E, et al. Affect Regulation, Mentalization, and the Development of the Self. New York: Other Press, 2002.

18. Lo C, Walsh A, Mikulincer M, et al. Measuring attachment security in patients with advanced cancer: psychometric properties of a modified and brief Experiences in Close Relationships scale. Psychooncology 2009; 18: 490-499.

19. Lo C, Zimmermann C, Gagliese L, Li M, Rodin G. Sources of spiritual well-being in advanced cancer. BMJ Support Palliat Care 2011; 1: 149-153.

20. Kirchmann H, Steyer R, Mayer A, et al. Effects of adult inpatient group psychotherapy on attachment characteristics: an observational study comparing routine care to an untreated comparison group. Psychother Res 2012; 22: 95-114.

21. Lo C, Hales S, Jung J, et al. Managing Cancer And Living Meaningfully (CALM): phase 2 trial of a brief individual psychotherapy in advanced cancer. Palliat Med 2014; 28: 234-242.

22. Kroenke K, Spitzer RL and Williams JBW. The PHQ-9: validity of a brief depression severity measure. J Gen Intern Med 2001; 16: 606-613.

23. Katzman $\mathrm{R}$, Brown T, Fuld $\mathrm{P}$, et al. Validation of a short orientation-memory-concentration test of cognitive impairment. Am J Psychiatry 1983; 140: 734-739.

24. Nissim R, Freeman E, Lo C, et al. Managing Cancer and Living Meaningfully (CALM): a qualitative study of a brief individual psychotherapy for individuals with advanced cancer. Palliat Med 2012; 26: 713-721. 
25. Ellis J, Lin J, Walsh A, et al. Predictors of referral for specialized psychosocial oncology care in patients with metastatic cancer: the contributions of age, distress and marital status. J Clin Oncol 2009; 27: 699-705.

26. Portenoy RK, Thaler HT, Kornblith AB, et al. The Memorial Symptom Assessment Scale: an instrument for the evaluation of symptom prevalence, characteristics and distress. Eur J Cancer 1994; 30A: 1326-1336.

27. First MB, Spitzer RL, Gibbon M, et al. Structured Clinical Interview for DSM-IV-TR Axis I DisordersPatient Edition (SCID-I/P, 1/2010 revision). New York, NY: New York State Psychiatric Institute, 2010.

28. Spitzer RL, Kroenke K, Williams JB, et al. A brief measure for assessing generalized anxiety disorder: the GAD-7. Arch Intern Med 2006; 166: 1092-1097.

29. Krause S, Rydall A, Hales S, et al. Initial validation of the Death and Dying Distress Scale for the assessment of death anxiety in advanced cancer. J Pain Symptom Manage. 2015; 49: 126-134.

30. Peterman AH, Fitchett G, Brady MJ, et al. Measuring spiritual well-being in people with cancer: the Functional Assessment of Chronic Illness Therapy - Spiritual Well-Being Scale (FACIT-Sp). Ann Behav Med 2002; 24: 49-58.

31. Rosenberg M. Society and the Adolescent Self-Image. Middletown, England: Wesleyan University Press, 1989.

32. Bond FW, Hayes SC, Baer RA, et al. Preliminary psychometric properties of the Acceptance and Action Questionnaire-II: a revised measure of psychological inflexibility and experiential avoidance. Behav Ther 2011; 42: 676-688.

33. Lo C, Burman D, Swami N, et al. Validation of the QUAL-EC for assessing quality of life in patients with advanced cancer. Eur J Cancer 2011; 47: 554-560.

34. Tedeschi RG and Calhoun LG. The Posttraumatic Growth Inventory: measuring the positive legacy of trauma. J Traumatic Stress 1996; 9: 455-471.

35. Kolden GG, Strauman TJ, Gittleman M, et al. The Therapeutic Realizations Scale-Revised (TRS-R): psychometric characteristics and relationship to treatment process and outcome. J Clin Psychol 2000; 56: 1207-1220.

36. Hertzog MA. Considerations in determining sample size for pilot studies. Res Nurs Health 2008; 31: 180-191.

37. SAS Institute Inc. SAS/STAT, version 9.3, SAS System. (C2002-2010, Cary, NC, USA. 
38. Spiegelhalter DJ, Abrams KR and Myles JP. Bayesian Approaches to Clinical Trials and Health-Care Evaluation. Chichester, England: Wiley, 2004, pp. 49-78.

39. Gurrin LC, Kurinczuk JJ and Burton PR. Bayesian statistics in medical research: an intuitive alternative to conventional data analysis. J Eval Clin Pract 2000; 6: 193-204.

40. Akechi T, Okuyama T, Onishi J, et al. Psychotherapy for depression among incurable cancer patients. Cochrane Database Syst Rev 2008 Apr 16; 2: CD005537. 
Table 1. Baseline characteristics $(N=60)$.

\begin{tabular}{|c|c|c|}
\hline Variable & $\begin{array}{l}\text { Usual care }(n=30) \\
M(S D) \text { or } \% \\
\text { (frequency) }\end{array}$ & $\begin{array}{l}\text { CALM (n=30) } \\
\text { M (SD) or \% } \\
\text { (frequency) }\end{array}$ \\
\hline Age in years & $56.62(11.36)$ & $55.37(12.13)$ \\
\hline Female & $73 \%(22)$ & $67 \%(20)$ \\
\hline Caucasian & $90 \%(27)$ & $93 \%(28)$ \\
\hline Married/common law & $67 \%(20)$ & $67 \%(20)$ \\
\hline Living alone & $20 \%(6)$ & $20 \%(6)$ \\
\hline Post-secondary education & $80 \%(24)$ & $87 \%(26)$ \\
\hline \multicolumn{3}{|l|}{ Annual household income } \\
\hline$<\$ 30,000$ & $13 \%(4)$ & $10 \%(3)$ \\
\hline$\$ 30,000-\$ 59,999$ & $17 \%(5)$ & $27 \%(8)$ \\
\hline$\$ 60,000-\$ 99,999$ & $27 \%(8)$ & $20 \%(6)$ \\
\hline$\$ 100,000+$ & $30 \%(9)$ & $27 \%(8)$ \\
\hline Did not respond & $13 \%(4)$ & $17 \%(5)$ \\
\hline Years since cancer diagnosis & $2.39(2.86)$ & $2.69(2.75)$ \\
\hline \multicolumn{3}{|l|}{ Disease site } \\
\hline Breast & $20 \%(6)$ & $7 \%(2)$ \\
\hline Endocrine & $0 \%(0)$ & $3 \%(1)$ \\
\hline Gastrointestinal & $37 \%(11)$ & $57 \%(17)$ \\
\hline Genitourinary & $10 \%(3)$ & $13 \%(4)$ \\
\hline Gynecological & $27 \%(8)$ & $17 \%(5)$ \\
\hline Lung & $7 \%(2)$ & $3 \%(1)$ \\
\hline Physical symptom count & $12.50(4.08)$ & $11.57(5.20)$ \\
\hline Physical symptom severity & $0.77(0.33)$ & $0.72(0.42)$ \\
\hline PHQ-9 & $8.03(4.46)$ & $7.27(5.38)$ \\
\hline $\mathrm{MDD}^{\mathrm{a}}$ & $14 \%(4)$ & $18 \%(5)$ \\
\hline GAD-7 & $5.63(4.90)$ & $4.97(4.15)$ \\
\hline Death anxiety & $34.73(18.58)$ & $32.38(21.86)$ \\
\hline Spiritual wellbeing & $30.00(9.19)$ & $30.48(9.72)$ \\
\hline Attachment anxiety & $18.63(6.98)$ & $23.57(9.84)$ \\
\hline Attachment avoidance & $20.73(9.73)$ & $25.26(9.04)$ \\
\hline Self-esteem & $33.37(4.50)$ & $32.03(5.84)$ \\
\hline Experiential avoidance & $27.43(8.71)$ & $31.03(11.72)$ \\
\hline Quality of life & $47.83(8.40)$ & $47.47(9.56)$ \\
\hline Posttraumatic growth & $53.10(19.86)$ & $57.43(23.46)$ \\
\hline
\end{tabular}

$\mathrm{M}=$ mean. $\mathrm{SD}=$ standard deviation.

${ }^{a}$ Usual care $(n=29) ; \operatorname{CALM}(n=28)$. 
Table 2. Change score thresholds for clinical improvement.

\begin{tabular}{|l|l|l|l|}
\hline Outcome & $\begin{array}{l}\boldsymbol{\Delta}_{\text {t2-to }} \\
\text { threshold }\end{array}$ & $\begin{array}{l}\text { Pooled } \\
\text { SD of } \\
\boldsymbol{\Delta}_{\text {t2-to }}\end{array}$ & $\begin{array}{l}\text { Effect size } \\
\mathbf{d}_{\text {t2-to }}\end{array}$ \\
\hline PHQ-9 & -2 & 5.11 & 0.39 \\
\hline GAD-7 & -2 & 5.29 & 0.38 \\
\hline Death anxiety & -7 & 16.35 & 0.43 \\
\hline Spiritual wellbeing & +2 & 5.87 & 0.34 \\
\hline Attachment anxiety & -3 & 6.65 & 0.45 \\
\hline Attachment avoidance & -3 & 6.85 & 0.44 \\
\hline Self-esteem & +2 & 3.32 & 0.60 \\
\hline Experiential avoidance & -3 & 7.15 & 0.42 \\
\hline Quality of life & +3 & 6.71 & 0.45 \\
\hline Posttraumatic growth & +8 & 20.53 & 0.39 \\
\hline
\end{tabular}

$\Delta_{\mathrm{t} 2 \text {-to }}$ threshold $=$ change score threshold. $\mathrm{t} 0=$ baseline assessment. $\mathrm{t} 2=6$ month assessment. $\mathrm{SD}=$ standard deviation. 
Table 3. Odds of improvement and depression diagnosis.

\begin{tabular}{|c|c|c|c|c|c|c|}
\hline & Usual care & CALM & $\begin{array}{l}\text { CALM: } \\
\text { Usual care }\end{array}$ & Usual care & CALM & $\begin{array}{l}\text { CALM: } \\
\text { Usual care }\end{array}$ \\
\hline Outcome & $\begin{array}{l}\text { Odds of } \\
\text { improve- } \\
\text { ment at t1 }\end{array}$ & $\begin{array}{l}\text { Odds of } \\
\text { improve- } \\
\text { ment at t1 }\end{array}$ & $\begin{array}{l}\text { Odds ratio } \\
\text { at t1 }\end{array}$ & $\begin{array}{l}\text { Odds of } \\
\text { improve- } \\
\text { ment at t2 }\end{array}$ & $\begin{array}{l}\text { Odds of } \\
\text { improve- } \\
\text { ment at t2 }\end{array}$ & $\begin{array}{l}\text { Odds ratio } \\
\text { at t2 }\end{array}$ \\
\hline PHQ-9 & $7: 19$ & $14: 10$ & 3.80 & $10: 11$ & $16: 8$ & 2.20 \\
\hline GAD-7 & $12: 12$ & $9: 13$ & 0.69 & 10:11 & $10: 14$ & 0.79 \\
\hline Death anxiety & $11: 13$ & $10: 12$ & 0.98 & $10: 11$ & $8: 15$ & 0.59 \\
\hline Spiritual wellbeing & $11: 13$ & $13: 9$ & 1.71 & $14: 7$ & $12: 12$ & 0.50 \\
\hline Attachment anxiety & $6: 18$ & $14: 8$ & 5.95 & $6: 15$ & $13: 11$ & 2.95 \\
\hline Attachment avoidance & $9: 15$ & $8: 14$ & 0.95 & $6: 15$ & $12: 12$ & 2.50 \\
\hline Self-esteem & $6: 18$ & $6: 16$ & 1.13 & $8: 13$ & $5: 19$ & 0.43 \\
\hline Experiential avoidance & $11: 13$ & $12: 10$ & 1.42 & $11: 10$ & 9:15 & 0.55 \\
\hline Quality of life & $10: 14$ & $5: 17$ & 0.42 & $10: 11$ & $12: 12$ & 1.10 \\
\hline \multirow[t]{3}{*}{ Posttraumatic growth } & $8: 16$ & $5: 17$ & 0.59 & 10:11 & $9: 15$ & 0.66 \\
\hline & & & $\begin{array}{l}\text { Usual care: } \\
\text { CALM }\end{array}$ & & & $\begin{array}{l}\text { Usual care: } \\
\text { CALM }\end{array}$ \\
\hline & $\begin{array}{l}\text { Odds of } \\
\text { diagnosis } \\
\text { at } \mathrm{t1}\end{array}$ & $\begin{array}{l}\text { Odds of } \\
\text { diagnosis } \\
\text { at } \mathrm{t} 1\end{array}$ & $\begin{array}{l}\text { Odds ratio } \\
\text { at t1 }\end{array}$ & $\begin{array}{l}\text { Odds of } \\
\text { diagnosis } \\
\text { at } t 2\end{array}$ & $\begin{array}{l}\text { Odds of } \\
\text { diagnosis } \\
\text { at } t 2\end{array}$ & $\begin{array}{l}\text { Odds ratio } \\
\text { at t2 }\end{array}$ \\
\hline MDD & $5: 21$ & $2: 22$ & 2.62 & $3: 16$ & $1: 22$ & 4.13 \\
\hline
\end{tabular}

Note. Odds are presented as the frequency of cases showing improvement vs. no improvement, or of cases with MDD diagnosis vs. no MDD diagnosis. Odds ratios for improvement compare CALM vs. Usual care, whereas odds ratios for MDD compare Usual care vs. CALM.

$\mathrm{t} 1=3$ month assessment. $\mathrm{t} 2=6$ month assessment. 
Table 4. Posterior distributions.

\begin{tabular}{|c|c|c|c|}
\hline & $\begin{array}{l}\text { CALM: Usual } \\
\text { Care }\end{array}$ & & \\
\hline Outcome & $\begin{array}{l}\text { Mean OR for } \\
\text { improvement }\end{array}$ & $\begin{array}{l}\text { 95\% Credible } \\
\text { interval }\end{array}$ & $\begin{array}{l}\text { Probability of } \\
\text { OR }>1.25\end{array}$ \\
\hline PHQ-9 & 1.48 & $0.65,3.38$ & 0.66 \\
\hline GAD-7 & 0.89 & $0.39,2.01$ & 0.21 \\
\hline Death anxiety & 0.77 & $0.33,1.77$ & 0.13 \\
\hline Spiritual wellbeing & 0.71 & $0.31,1.63$ & 0.09 \\
\hline Attachment anxiety & 1.72 & $0.73,4.03$ & 0.76 \\
\hline Attachment avoidance & 1.58 & $0.67,3.71$ & 0.71 \\
\hline Self-esteem & 0.66 & $0.27,1.62$ & 0.08 \\
\hline Experiential avoidance & 0.74 & $0.33,1.69$ & 0.11 \\
\hline Quality of life & 1.05 & $0.47,2.36$ & 0.34 \\
\hline \multirow[t]{3}{*}{ Posttraumatic growth } & 0.81 & $0.36,1.85$ & 0.15 \\
\hline & $\begin{array}{l}\text { Usual care: } \\
\text { CALM }\end{array}$ & & \\
\hline & $\begin{array}{l}\text { Mean OR for } \\
\text { diagnosis }\end{array}$ & $\begin{array}{l}\text { 95\% Credible } \\
\text { interval }\end{array}$ & $\begin{array}{l}\text { Probability of } \\
\text { OR }>1.25\end{array}$ \\
\hline MDD & 1.56 & $0.50,4.84$ & 0.65 \\
\hline
\end{tabular}

Note. Odds ratios for improvement compare CALM vs. Usual care, whereas odds ratios for MDD compare Usual care vs. CALM.

$\mathrm{OR}=$ odds ratio. 
Table 5. Self-reported therapeutic benefit.

\begin{tabular}{|c|c|c|}
\hline Item & $\begin{array}{l}\mathrm{t1} M(S D) \\
(\mathrm{n}=21)\end{array}$ & $\begin{array}{l}\text { t2 M (SD) } \\
(n=20)\end{array}$ \\
\hline A chance to let go and express feelings & $1.90(1.09)$ & $2.05(0.89)$ \\
\hline Hope: a feeling that things can work out & $1.33(0.97)$ & $1.50(0.83)$ \\
\hline Help in talking about what was really troubling me & $1.43(1.16)$ & $1.75(0.85)$ \\
\hline Relief from tensions or unpleasant feelings & $1.14(1.01)$ & $1.60(0.99)$ \\
\hline $\begin{array}{l}\text { More understanding of reasons behind my behavior and } \\
\text { feelings }\end{array}$ & $1.33(1.11)$ & $1.60(0.99)$ \\
\hline Reassurance and encouragement about how I'm doing & $1.81(0.93)$ & $1.75(0.97)$ \\
\hline Confidence to try to do things differently & $1.43(0.98)$ & $1.35(1.04)$ \\
\hline Ideas for better ways of dealing with people and problems & $1.14(1.01)$ & $1.50(1.00)$ \\
\hline Better self-control over my moods and actions & $0.90(0.94)$ & $1.15(0.81)$ \\
\hline $\begin{array}{l}\text { Increased awareness that thoughts and/or feelings } \\
\text { experienced now are similar to those in the past }\end{array}$ & $1.19(1.03)$ & $1.37(0.76)$ \\
\hline $\begin{array}{l}\text { Increased awareness that reactions and behaviors toward } \\
\text { someone now are similar to reactions and behaviors } \\
\text { towards others in the past }{ }^{a, b}\end{array}$ & $1.00(0.86)$ & $1.05(0.91)$ \\
\hline $\begin{array}{l}\text { A chance to try out or practice a new skill or way of } \\
\text { behaving }\end{array}$ & $0.86(0.96)$ & $0.90(0.97)$ \\
\hline $\begin{array}{l}\text { Education: information about symptoms, problems, or } \\
\text { people }\end{array}$ & $1.29(1.10)$ & $1.15(1.04)$ \\
\hline Total score & $16.79(10.23)$ & $18.69(8.82)$ \\
\hline
\end{tabular}

$\mathrm{M}=$ mean. $\mathrm{SD}=$ standard deviation. $\mathrm{t} 1=3$ month assessment. $\mathrm{t} 2=6$ month assessment.

${ }^{a} t 2(n=19) .{ }^{b} t(n=20)$. 
Figure 1. Patient flow diagram.

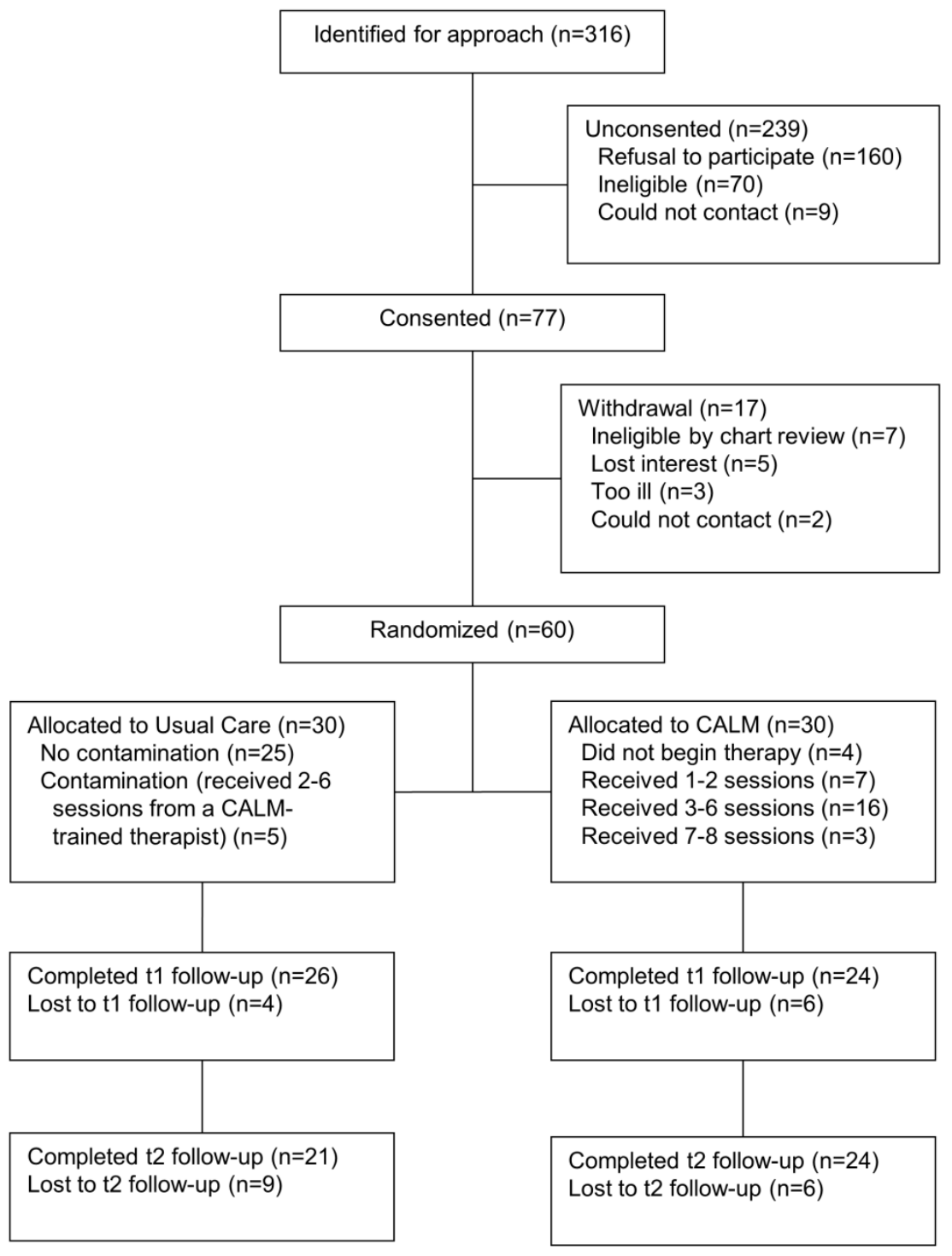

